\title{
Finite element analysis of soft foundation treatment by thermal drainage consolidation of group well
}

\author{
Kang Le ${ }^{1}$, Zhang tingjun ${ }^{1}$, Tong Junhui ${ }^{1}$, Chen $\mathrm{Di}^{2}$, Qian Baoyuan ${ }^{2 *}$ \\ ${ }^{1}$ Ningbo Municipal Engineering Prophase Office, Ningbo 315211, China; \\ ${ }^{2}$ Institution of geotechnical engineering, Ningbo University, Ningbo 315211 , China
}

\begin{abstract}
Thermal drainage consolidation method is a new technology of soft foundation treatment, which involves the coupling of thermo-hydro-mechanical field, and the action mechanism is complex. In this paper, taking the model test of thermal drainage consolidation as the prototype, the finite element model of thermal drainage consolidation is established by using Abaqus software, then, the numerical results are obtained and are compared with the results of model test, and the reliability of the numerical model is verified. The results show that when the applied load is constant, the higher the temperature is, the faster the consolidation speed of soil is, but with the increase of temperature, the consolidation effect of the same temperature difference will gradually weaken. In addition, the thermal drainage consolidation method can achieve the best treatment effect when the temperature of the soil reaches $60{ }^{\circ} \mathrm{C}$.
\end{abstract}

\section{INTRODUCTION}

As an economical and effective method, drainage consolidation method has been widely used in the soft foundation treatment. Because the traditional drainage consolidation method often takes a long time to deal with soft clay foundation, and in the construction process of plastic drainage board or sand well, it will produce inevitable smear effect, which will affect the action of soft foundation treatment to a certain extent[1-4]. The "thermal drainage consolidation method" is a new technology developed on the basis of the traditional drainage consolidation method, in which a heat conduction pipe is added to the plastic drainage plate or sand well to increase the temperature and permeability coefficient of the surrounding soil through heat transmission, and to accelerate consolidation settlement of the foundation[5].

There are some literatures on thermal drainage consolidation method, for example, Tao et al. [6] took the classical shaft foundation as an example to carry out finite element calculation, and analyze the acceleration effect of temperature on foundation consolidation and drainage. Yin etal.[7] carried out the thermal consolidation test of saturated soft clay at $30{ }^{\circ} \mathrm{C}, 45{ }^{\circ} \mathrm{C}, 60{ }^{\circ} \mathrm{C}$ and $75^{\circ} \mathrm{C}$, it is shown that the higher the temperature is, the greater the permeability coefficient of soft clay is, which accelerates the discharge of pore water from the soil and reduces the consolidation time of the soil. Liu[8] designed a model test system of thermal drainage consolidation, in which the the typical soft clay in Ningbo area is selected, and the variation of temperature, pore water pressure and surface settlement in the soil are analyzed.
In this paper, the finite element model, according to the actual size of the thermal plastic drainage plate and soil in the model test, is established by using Abaqus program, then, the numerical results are obtained and are compared with the results of the model test. Furthermore, the reliability of the finite element model is verified, and the effect of thermal drainage consolidation is analyzed, which provides technical support for the application of thermal drainage consolidation method.

\section{MODEL TEST}

A steel model box of $2 \mathrm{~m} \times 2 \mathrm{~m} \times 1.2 \mathrm{~m}$ (length $\times$ width $\times$ height) is used in the thermal drainage consolidation test of group well foundation, in which the fill height of the muddy silty clay is $1.0 \mathrm{~m}$ and the diameter of the shaft is $10 \mathrm{~cm}$. The layout of the measuring points is shown in the figure 1 and there are two cases of test temperature for four equivalent sand well, i.e., $26{ }^{\circ} \mathrm{C}$ and $26{ }^{\circ} \mathrm{C} \rightarrow$ $50{ }^{\circ} \mathrm{C} \rightarrow 65^{\circ} \mathrm{C} \rightarrow 26{ }^{\circ} \mathrm{C}$.

\footnotetext{
* Corresponding author: 79967135@qq.com
} 


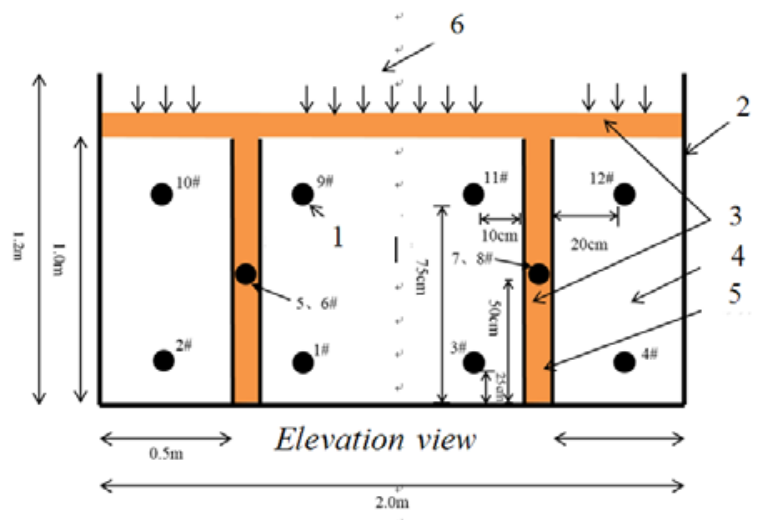

1-Integrated sensor of pore pressure and temperature;2-Model box; 3-Medium sand;4-Muddy silty clay;5-Equivalent sand well;6-Uniformly distributed load $12.5 \mathrm{kPa}$

Fig. 1 test points for model test

Because of the symmetry of shaft layout and sensor arrangement in the model test, the analysis results of temperature and excess pore water pressure will take the average of the readings of two symmetrical position sensors. For example, the average values of sensors 1 and 3 are taken as the results of measuring points, those of sensors 2 and 4 are measured point results, those of sensors 5 and 7 are measured point results, and the average values of sensors 6 and 8 are measured point results. 9 and 11 are the results of the test points, and 10 and 12 are the results of the test points.

\section{FEM MODEL AND VERIFICATION}

\section{(1) Basic assumptions}

The soil isassumpted to be isotropic and homogeneous saturated, and the modified Cambridge model is adopted. The initial temperature of soil is uniformly distributed. Without considering the flow of water in the pipe, the equivalent sand well of the thermal plastic drainage plate is regarded as the ideal heat source. Because the U-shaped tube in the shaft is distributed near the edge of the shaft, the heat source is distributed along the edge of the shaft.The shaft and soil are regarded as the same material, only the difference of permeability coefficient between shaft and soil is considered, and other mechanical parameters are consistent. Only the influence of temperature on critical state parameter $M$ and soil permeability coefficient $k$ is considered, but the changes of other soil physical parameters are not considered.

(2) Geometric model

Taking the thermal drainage consolidation model test as the prototype, as shown in figure 1, the soil used in the model test is muddy silty clay in Ningbo area, and the model box is $2 \mathrm{~m} \times 2 \mathrm{~m} \times 1.2 \mathrm{~m}$ (length $\times$ width $\times$ height $)$. Four thermal conductive plastic drainage plates (plastic drain plate and heat conduction pipe connected "U" type) are used for thermal drainage, which are equivalent to sand wells with $10 \mathrm{~cm}$ diameter and symmetrically distributed, and U-shaped pipes are symmetrically distributed. In order to use the plane equivalent method for analysis, the width of the model box is intercepted as the calculation domain; in practice, a single shaft is taken as a cylinder as the analysis object, and under the twodimensional equivalent model, the shaft diameter is taken as the trench wall as the analysis object, as shown in figure 2 . The thickness of the soil layer is $1.0 \mathrm{~m}$, the spacing of sand wells is $1 \mathrm{~m}$, it runs through the soil, and the model parameters are shown in Table 1.

Tab. 1 Parameters of model

\begin{tabular}{|c|c|c|c|}
\hline Parameters & values & Parameters & values \\
\hline $\begin{array}{l}\text { critical state } \\
\text { parameter } M\end{array}$ & 1.15 & poisson's ratio $v$ & 0.35 \\
\hline $\begin{array}{l}\text { compression } \\
\text { coefficient } \lambda\end{array}$ & 0.15 & void ratio $e_{1}$ & 2.0 \\
\hline $\begin{array}{c}\text { specific heat } \\
\text { capacity of soil } \\
\mathrm{KJ} / \mathrm{kg} / \mathrm{K}\end{array}$ & 1.52 & $\begin{array}{c}\text { rebound } \\
\text { coefficient } \kappa\end{array}$ & 0.045 \\
\hline $\begin{array}{c}\text { heavy weight } \\
\gamma / \mathrm{kN} / \mathrm{m}^{3}\end{array}$ & 18.0 & $\begin{array}{c}\text { thermal } \\
\text { conductivity of } \\
\text { soil } \\
\mathrm{W} / \mathrm{m} / \mathrm{K}\end{array}$ & 1.51 \\
\hline $\begin{array}{l}\text { coefficient of } \\
\text { linear expansion } \\
\text { of soil } \\
{ }^{\circ} \mathrm{C}^{-1}\end{array}$ & $1 \times 10^{-5}$ & $\begin{array}{c}\text { soil permeability } \\
\text { coefficient } k \\
\mathrm{~cm} / \mathrm{s}\end{array}$ & $2 \times 10^{-7}$ \\
\hline
\end{tabular}

(3) Initial and boundary conditions

The initial displacement and pore pressure of foundation soil are 0 . The top stress boundary of the model is uniformly distributed load, the lateral stress boundary is sliding bearing, the bottom stress boundary is fixed support, and the surface of soil is drainage interface. In order to simulate the actual process of threestage loading in the model test, three analysis steps are used to apply loading. The finite element model of thermal drainage consolidation of shaft foundation: the initial temperature of foundation soil is $26{ }^{\circ} \mathrm{C}$, the initial displacement and pore pressure are 0 . The temperature boundary of the top, side and bottom of the soil is $26^{\circ} \mathrm{C}$. In order to simulate the actual heating curve of Ushaped tube in shaft, the change of temperature with time is realized by adding temperature amplitude curve when temperature load is applied. The top stress boundary of the model is uniformly distributed load, the lateral stress boundary is sliding bearing, the bottom stress boundary is fixed support, and the soil surface is drainage interface. Six analysis steps are used to simulate the whole test process.

\section{(4) Meshing}

The soil element adopts quadrilateral swept grid technology, pore pressure and stress coupling element type (CPE4P), and temperature element adopts heat transfer element type (DC2D4). The total number of elements is 1800 , and the node degrees of freedom include pore pressure, displacement and temperature, as shown in figure 2.

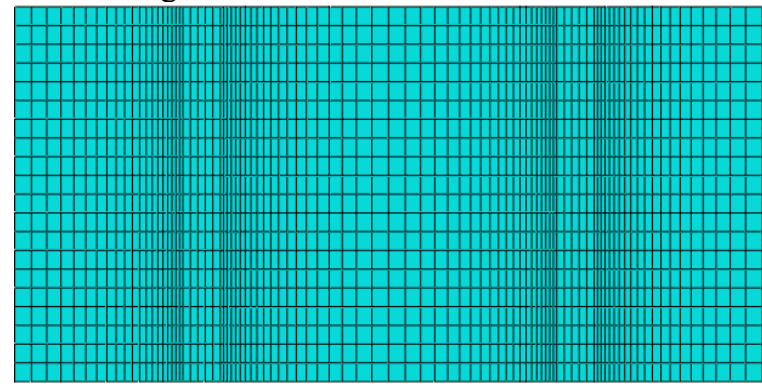

Fig. 2 Finite element model meshing diagram 
(5) Sequential thermal coupling.

A simple thermal analysis is carried out in the drainage consolidation model by using sequential thermal coupling.

(6) Verification of finite element model

Before the first stage loading, the ground stress of the soil is balanced in order to balance the initial deformation caused by the dead weight stress field. In order to simulate the actual process of thermal drainage consolidation model test, the finite element model is calculated in sections, and the calculation process is shown in tables 2 and 3 .

Tab.2 Loading phase

\begin{tabular}{|c|c|c|}
\hline $\begin{array}{l}\text { Calculation } \\
\text { phase }\end{array}$ & $\begin{array}{c}\text { Corresponding model test } \\
\text { stage }\end{array}$ & Initial value \\
\hline Step-1 & Rest for a week & Initial setting \\
\hline Step-2 & First stage loading $10.5 \mathrm{kPa}$ & Step-1 \\
\hline Step-3 & Second stage loading $10.5 \mathrm{kPa}$ & Step-2 \\
\hline Step-4 & Third stage loading $10.5 \mathrm{kPa}$ & Step3 \\
\hline \multicolumn{3}{|c|}{ Tab.3 Calculation process of finite element model } \\
\hline $\begin{array}{l}\text { Calculation } \\
\text { phase }\end{array}$ & $\begin{array}{c}\text { Corresponding model test } \\
\text { stage }\end{array}$ & Initial value \\
\hline Step-1 & Rest for a week & Initial setting \\
\hline Step-2 & $\begin{array}{l}\text { Raise the temperature until } \\
\text { the temperature is stable }\end{array}$ & Step-1 \\
\hline Step-3 & First stage loading $10.5 \mathrm{kPa}$ & Step-2 \\
\hline Step-4 & $\begin{array}{c}\text { Second stage loading } \\
10.5 \mathrm{kPa}\end{array}$ & Step-3 \\
\hline Step-5 & Third stage loading $10.5 \mathrm{kPa}$ & Step-4 \\
\hline Step-6 & $\begin{array}{l}\text { Heat up again until the } \\
\text { temperature is stable }\end{array}$ & Step-5 \\
\hline Step-7 & Natural cooling & Step-6 \\
\hline
\end{tabular}

\section{CALCULATION RESULTS}

The numerical results of the temperature, pore pressure and settlement are compared with those of the model test to verify the feasibility of the finite element model.

(1) temperature

After the thermal drainage consolidation test is heated at $26{ }^{\circ} \mathrm{C}, 50{ }^{\circ} \mathrm{C}$ and $65{ }^{\circ} \mathrm{C}$, the distribution nephogram of the soil when the temperature reaches a stable value is shown in Fig. 3, and the comparison curves of temperature between the model test and the numerical simulation are shown in figure 4.

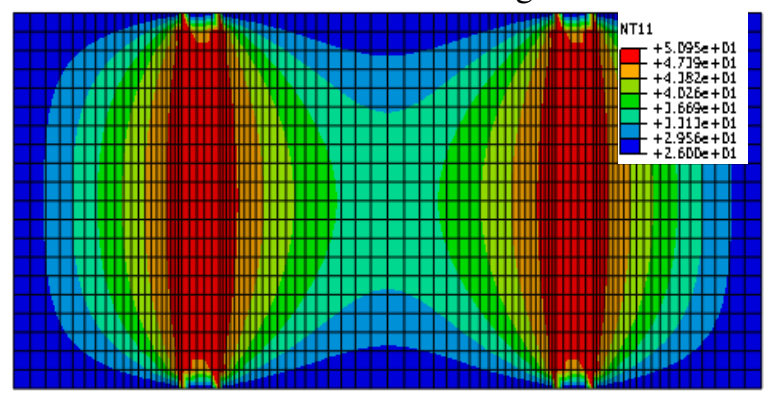

(a) heat source temperature $50{ }^{\circ} \mathrm{C}$

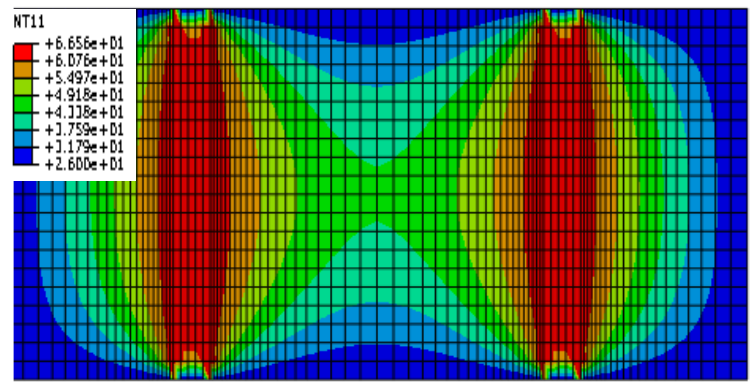

(b) heat source temperature $65{ }^{\circ} \mathrm{C}$

Fig.3 Diagram of soil temperature distribution

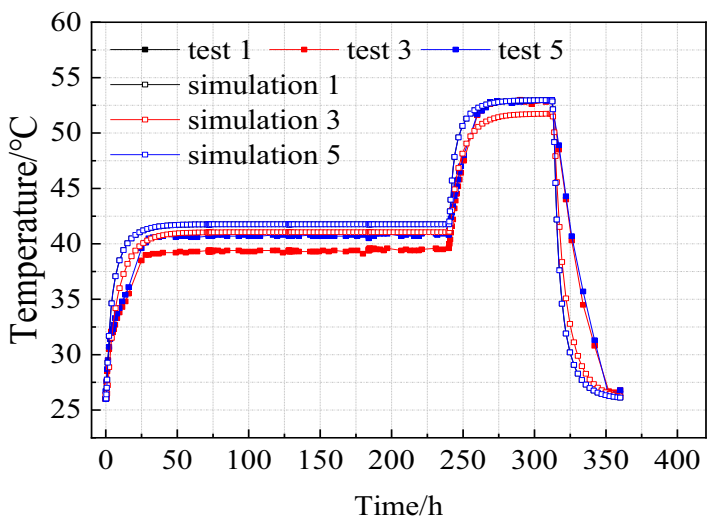

(a) 1, 3,5 test piont

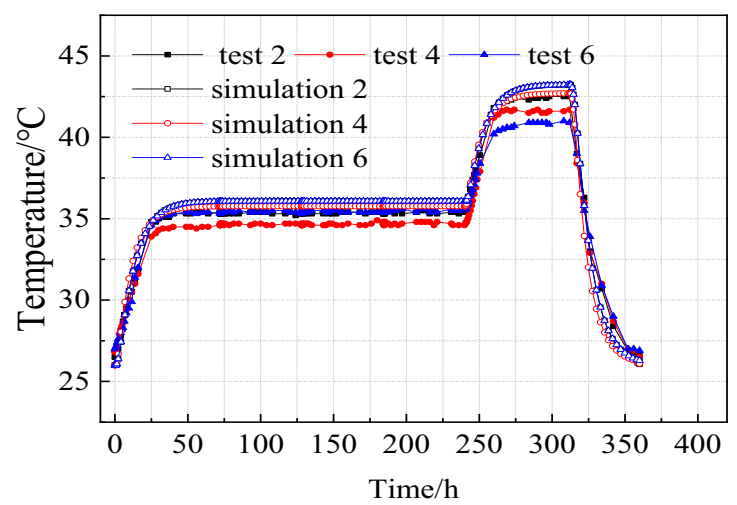

(b) 2, 4, 6 test piont

Fig.4 Comparison of temperature test value and simulation value

It can be seen from figure 4 that there is a slight difference between the test values and the simulation values, because the boundary condition used in the simulation is that the surrounding temperature is fixed, not the thermal radiation boundary. The simulation values of temperature for each sensor are in good agreement with the test values as a whole, and their development rules are basically the same.

(2) pore pressure

After heating, loading and cooling in the test of the thermal drainage consolidation, the distribution nephogram of pore pressure in the heating stage and cooling stage in the model test is shown in figure 5 . The comparison curves of the test values and the simulation value are shown in figure 6. 


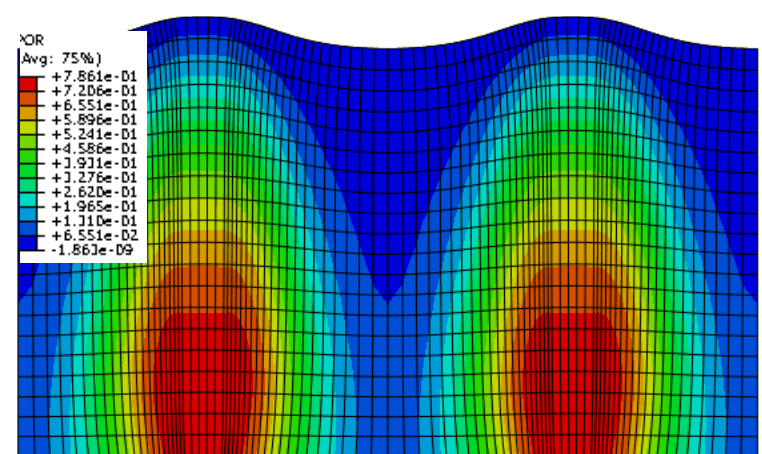

(a) Pore pressure distribution of soil in non-heap heating stage

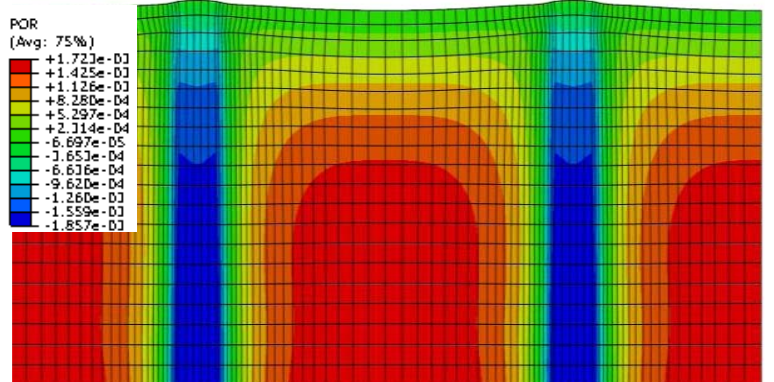

(b) Pore pressure distribution of soil in the stage of constant load cooling Fig.5 Pore pressure distribution of thermal drainage consolidation test

It can be seen from Fig. 6 that the simulation value of pore pressure increases at first, and then slowly dissipates to 0 in the first heating stage. In the stage of loading, the pore pressure development law is similar to that of the traditional drainage consolidation test, and the pore pressure test values (test piont $1 \sim 6$ ) is consistent with the simulation value(test point $1 \sim 6$ ). In the cooling stage, because the expansion coefficient of soil particles is less than that of pore water, the shrinkage rate is inconsistent, and the pore pressure decreases to a negative value, showing suction (it can be found through simulation that when the expansion coefficient of pore water is consistent with that of soil particles, the simulation results are that heating and cooling no longer cause the change of pore pressure). By observing the change of pore pressure caused by graded load, it can be seen that the dissipation rate of pore pressure increases with the application of loading.

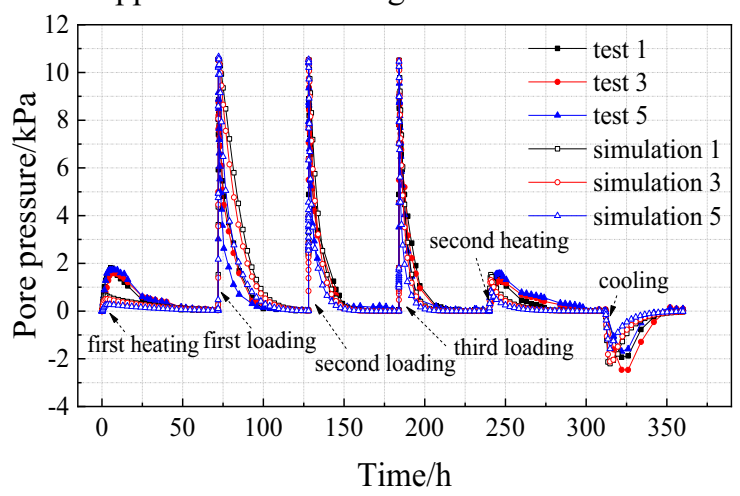

(a) 1, 3,5 test piont

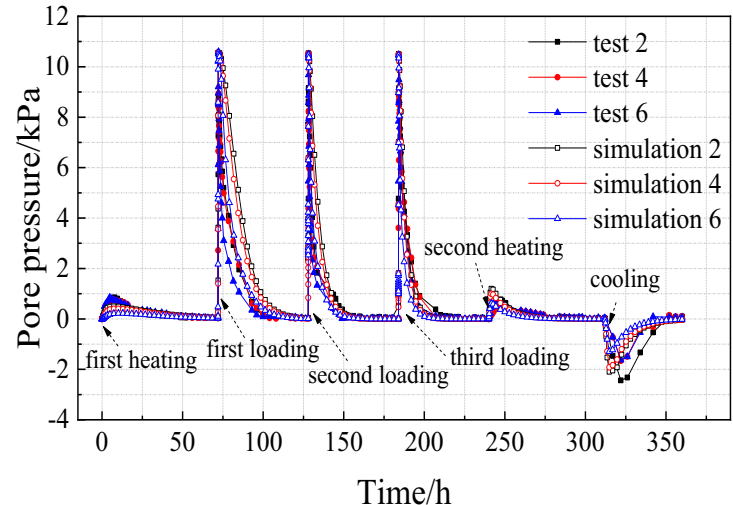

(b) 2, 4, 6 test piont

Fig.6 Comparison of pore-pressure of test value and simulation value

(3) Surface settlement

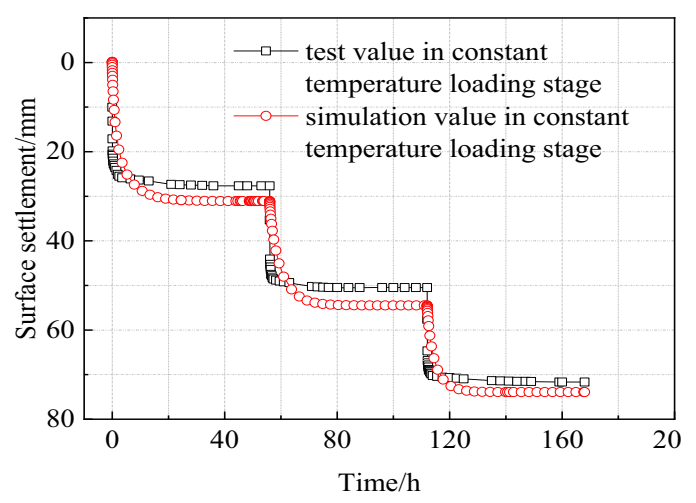

Fig.7 Settlements of calculation and model test

The history of surface settlement for the test and simulation of sand well foundation under the action of temperature are shown in Fig.7. In the loading stage, the variation of the experimental value is consistent with that of the simulated value. The situation of the reheating of the soil is similar to that of the non-loading heating stage. when the sand well stops heating, the soil settlement increases rapidly, but the final settlement is quite different from the test value. this is because the settlement caused by simulated cooling is mainly caused by the thermal expansion and cold shrinkage of the soil.

\section{CONCLUSION}

The finite element method is used in this paper to simulate the thermal drainage consolidation of group well foundation, and the numerical results are obtained and are compared with the results of the model test. The main conclusions are as follows:

(1) The numerical results are in good agreement with those of the model test.The change of temperature will have an effect on the surface settlement of the foundation, in a certain temperature range, the settlement increases gradually with the increase of the temperature.

(2) When the load is constant, the higher the temperature is, the faster the consolidation speed of soil is, but with the increase of temperature, the consolidation effect of the same temperature difference will gradually weaken. When the temperature of the soil reaches $60^{\circ} \mathrm{C}$, the thermal drainage consolidation method can achieve the best treatment effect. 


\section{Acknowledgement}

This research was supported by the Ningbo Science and Technology Plan Project (No. 2017C510002) to which the author is grateful.

\section{References}

1. Gu L.S., Wang D.B., Ma X.L,. J. Waterway Harbor, 37,3(2016)

2. Lin G.J., Wan Z.G., Deng L.F., J. Waterway Harbor, 39,6(2018)

3. Lei H. Y., Lu H. B., Liu J.J., et al., Int. J. Geom., 17,12(2017)

4. Wang J., Cai Y.Q., Fu H.T, et al., Chinese J. Rock Mech. Eng. 33,6(2014)

5. POTHIRAKSANON C., DENNES T.B., ABUELNAGA H. M., Soils Foundations 50,5(2010)

6. Tao H.B., Xie K.H., Liu G.B., Huang D.Z., Deng Y.B., Rock Soil Mech. 34,S1(2013)

7. Yin T.F., Liu G.B., Guo Z., Building Struc.8(2014).

8. Liu G.B., Fan G.F., Tao H.B., Yin T.F., Deng Y.B., J. C.S. Univ.(Sci. Tech) 28, 2(2017) 